\title{
Tissue damage by laser radiation: an in vitro comparison between Tm:YAG and Ho:YAG laser on a porcine kidney model
}

\author{
Stephan Huusmann ${ }^{1 *}$, Mathias Wolters ${ }^{1}$, Mario W. Kramer ${ }^{5}$, Thorsten Bach², Heinrich-Otto Teichmann ${ }^{3}$, \\ Andreas Eing ${ }^{3}$, Sebastian Bardosi ${ }^{4}$ and Thomas R. W. Herrmann ${ }^{1 *}$
}

\begin{abstract}
The understanding of tissue damage by laser radiation is very important for the safety in the application of surgical lasers. The objective of this study is to evaluate cutting, vaporization and coagulation properties of the $2 \mu \mathrm{m}$ Tm:YAG laser (LISA Laser Products OHG, GER) in comparison to the $2.1 \mu \mathrm{m}$ Ho:YAG laser (Coherent Medical Group, USA) at different laser power settings in an in vitro model of freshly harvested porcine kidneys. Laser radiation of both laser generators was delivered by using a laser fiber with an optical core diameter of $550 \mu \mathrm{m}$ (RigiFib, LISA Laser GER). Freshly harvested porcine kidneys were used as tissue model. Experiments were either performed in ambient air or in aqueous saline. The Tm:YAG laser was adjusted to $5 \mathrm{~W}$ for low and $120 \mathrm{~W}$ for the high power setting. The Ho:YAG laser was adjusted to $0.5 \mathrm{~J}$ and $10 \mathrm{~Hz}$ ( $5 \mathrm{~W}$ average power) for low power setting and to $2.0 \mathrm{~J}$ and $40 \mathrm{~Hz}$ ( $80 \mathrm{~W}$ average power) for high power setting, accordingly. The specimens of the cutting experiments were fixed in $4 \%$ formalin, embedded in paraffin and stained with Toluidin blue. The laser damage zone was measured under microscope as the main evaluation criteria. Laser damage zone consists of an outer coagulation zone plus a further necrotic zone. In the ambient air experiments the laser damage zone for the low power setting was $745 \pm 119 \mu \mathrm{m}$ for the Tm:YAG and $614 \pm 187 \mu \mathrm{m}$ for the Ho:YAG laser. On the high power setting, the damage zone was $760 \pm 167 \mu \mathrm{m}$ for Tm:YAG and $715 \pm 142 \mu \mathrm{m}$ for Ho:YAG. The incision depth in ambient air on the low power setting was $346 \pm 199 \mu \mathrm{m}$ for Tm:YAG, $118 \pm 119 \mu \mathrm{m}$ for Ho:YAG. On the high power setting incision depth was $5083 \pm 144 \mu \mathrm{m}$ (Tm:YAG) and $1126 \pm 383 \mu \mathrm{m}$ (Ho:YAG) respectively. In the saline solution experiments, the laser damage zone was $550 \pm 137 \mu \mathrm{m}$ (Tm:YAG) versus $447 \pm 65 \mu \mathrm{m}$ (Ho:YAG), on the low power setting and $653 \pm 137 \mu \mathrm{m}$ (Tm:YAG) versus $677 \pm 134 \mu \mathrm{m}$ (Ho:YAG) on the high power setting. Incision depth was $1214 \pm 888 \mu \mathrm{m}$ for Ho:YAG whereas Tm:YAG did not cut tissue at $5 \mathrm{~W}$ in saline solution. On the high power setting, the incision depth was $4050 \pm 1058 \mu \mathrm{m}$ for Tm:YAG and $4083 \pm 520 \mu \mathrm{m}$ for Ho:YAG. Both lasers create similar laser damage zones of $<1 \mathrm{~mm}$ in ambient air and in saline solution. These in vitro experiments correspond well with in vivo experiments. Thereby, Tm:YAG offers a cutting performance, coagulation and safety profile similar to the standard Ho:YAG lasers in urological surgery.
\end{abstract}

Keywords: Tm:YAG, Ho:YAG, Laser effects, Tissue damage

\section{Background}

Over the past few years, several laser devices were introduced in urologic surgery. The pulsed holmium:YAG

\footnotetext{
*Correspondence: Huusmann.stephan@mh-hannover.de; Herrmann.thomas@mh-hannover.de

1 Department of Urology and Urological Oncology, Hannover Medical School (MHH), Carl Neuberg Str. 1, 30625 Hannover, Germany

Full list of author information is available at the end of the article
}

(Ho:YAG) laser, with a wavelength of $2123 \mathrm{~nm}$, is the most commonly used laser because of its wide field of application regarding tissue surgery and stone treatment. This energy source has become the standard tool for intracorporal lithotripsy in percutaneous or retrograde intrarenal surgery (Gupta 2007; Pierre and Preminger 2007). With water as the chromophore the Ho:YAG laser radiation is highly absorbed in any water containing material, such as tissue or urinary stones, leading to an

\section{至 Springer}

(c) 2016 Huusmann et al. This article is distributed under the terms of the Creative Commons Attribution 4.0 International License (http://creativecommons.org/licenses/by/4.0/), which permits unrestricted use, distribution, and reproduction in any medium, provided you give appropriate credit to the original author(s) and the source, provide a link to the Creative Commons license, and indicate if changes were made. 
instant vaporization and a low penetration depth (Herrmann et al. 2012; Teichmann et al. 2007).

The continuous wave thulium:YAG (Tm:YAG) laser, with a wavelength of $2013 \mathrm{~nm}$, was introduced as an alternative laser for tissue surgery, especially for prostate surgery (Bach et al. 2007, 2010; Fried and Murray 2005). In addition, the Tm:YAG laser radiation is absorbed by water molecules. Further ex vivo studies proved increased tissue ablation capacity, shallower and even tissue penetration depth, and equal hemostatic properties when compared to the potassium-titanyl-phosphate-laser (KTP) and lithiumborate-laser (LBO) (Herrmann et al. 2012; Bach et al. 2010; Heinrich et al. 2010; Wendt-Nordahl et al. 2008).

In the present in vitro study, the Tm:YAG laser (RevoLix 120 Thulium laser, LISA Laser Products OHG, Katlenburg-Lindau, Germany) was compared, with regard to the cutting, vaporization, and coagulation properties, to the Ho:YAG laser (VersaPulse Select Holmium laser, Coherent Medical Group, USA) as reference standard at different laser power settings on freshly harvested porcine cadaver kidneys. Based on the different physical properties of each laser system, additional ex vivo experiments are necessary to understand the effect on tissue and to assess the complications and the clinical outcome after surgery. The aim was to clarify whether the Tm:YAG laser offers comparable characteristics which may lead to comparable safety for surgical application. The data of this study was used to formally clear the acceptance of the medical board of japan guaranteeing efficacy and safety for the Tm:YAG laser with regard to the commonly accepted Ho:YAG laser.

\section{Methods}

The Tm:YAG laser (RevoLix 120 Thulium laser, LISA Laser Products OHG, Katlenburg-Lindau, Germany) emits laser radiation at a wavelength of $2013 \mathrm{~nm}$ in continuous wave fashion. The laser power is directly set in watt (W) because of the continuous wave mode.

The Ho:YAG laser (VersaPulse Select Holmium laser, by Coherent Medical Group, USA) emits laser radiation at a wavelength of $2123 \mathrm{~nm}$ in a pulsed manner. The output of the Ho:YAG laser is set separately for pulse energy in joule $(\mathrm{J})$ and pulse repetition rate in Hertz $(\mathrm{Hz})$. The multiplication of pulse energy $(\mathrm{J})$ and repetition rate $(\mathrm{Hz})$ is the average output power in watt (W).

For delivery of laser radiation a laser fiber with an optical core diameter of $550 \mu \mathrm{m}$ (RigiFib laser fiber, LISA, Katlenburg-Lindau, Germany) was used for both laser units. The fiber was cut prior to every single experiment by a scissor.

For handling purposes a handpiece guiding the laser fiber (SurgiLas 110-1.1, LISA Laser Products OHG, Katlenburg-Linda, Germany) was used.
Kidneys were harvested from freshly slaughtered pigs, rinsed in water and stored at $4-8{ }^{\circ} \mathrm{C}$ until the experiments were performed.

All results are given as arithmetic mean of three equal experiments for every setting.

\section{Experiments in ambient air}

Laser delivery to the tissue was carried out in a standardized setup. The tissue was cut under visual guidance. The angle of the handpiece with the fiber to the kidney surface was exactly $45^{\circ}$. Cutting was performed with a defined translation speed of $2 \mathrm{~mm} / \mathrm{s}$. The distance between the fiber tip and the tissue was $0.5 \mathrm{~mm}$. Three incisions with a length of $1 \mathrm{~cm}$ were performed on each power setting and classified for later identification.

For the histological preparation, the tissue samples were cut with a cold knife perpendicular to the laser incision and fixed in vials of $4 \%$ formalin for $48 \mathrm{~h}$.

The laser settings for the cutting experiments consisted of a low power and a high power setting. For the low power setting, the Tm:YAG laser was set to a laser power of $5 \mathrm{~W}$. The Ho:YAG laser was set to $0.5 \mathrm{~J}$ pulse energy with a repetition rate of $10 \mathrm{~Hz}$ which multiplies to an average laser power of $5 \mathrm{~W}$. On the high power setting, the Tm:YAG laser was set to the maximum power of $120 \mathrm{~W}$ of the Revolix generator. The Ho:YAG laser was set to $2.0 \mathrm{~J}$ pulse energy with a $40 \mathrm{~Hz}$ repetition rate multiplying to $80 \mathrm{~W}$ average laser power which represents the maximum of the VersaPulse Select generator.

\section{Experiments in aqueous saline solution}

For the experiments in aqueous saline solution, a transparent basin was filled with $0.9 \% \mathrm{NaCl}$ aqueous solution at $23{ }^{\circ} \mathrm{C}$. The kidneys were fixed to the bottom of the basin. The laser incisions were conducted in the same way as described in the laser incision experiments in ambient air. The power settings for the aqueous saline solution experiments were identical to those as used in the experiments in ambient air including a low power and a high power setting.

\section{Histological evaluation of tissue effect}

The depth of tissue vaporization (laser incision) and the width of the damage zones were measured under a microscope using a calibrated caliper.

For the histological evaluation the specimens was fixed in $4 \%$ formalin, they were embedded in paraffin. Serial slices with a thickness of $2-3 \mu \mathrm{m}$ were prepared and stained with toluidine blue, which had an advantage in circumscribing the E-zone compared to haematoxylin and eosin stain.

\section{Items: OC-zone, NT-zone, E-zone}

The outer coagulation zone (OC-zone) is defined as a carbonized seam and a tissue layer with vacuolization 
underneath. In toluidine blue staining, the OC-zone appears green blue or dark blue (Fig. 1). The necrotic tissue layer (NT-zone) is light blue in images. At high magnification, the pycnotic nuclei of the cells may be observed. The subsequent edema zone (E-zone) results from exposure to heat generated from absorbed laser energy. In vivo, the E-zone has the potential to recover thus it is considered not to be part of the laser damage zone. In histologic images it is slightly darker blue than the healthy tissue (Fig. 1).

By definition the laser damage zone consists of the outer coagulation zone plus the necrotic zone (Fig. 2).

Furthermore the incision depth created by the vaporization of tissue due to absorption of laser radiation is evaluated in this study (Fig. 2). It indicates the surgical incision into the tissue under the above mentioned conditions.

\section{Results}

\section{Experiments in ambient air}

The low power setting (5 W) showed comparable laser damage zones for both lasers, amounting to $745 \pm 119 \mu \mathrm{m}$ for Tm:YAG and $614 \pm 187 \mu \mathrm{m}$ for Ho:YAG (Tables 1, 2). The high power setting experiments lead to laser damage zones of $760 \pm 167 \mu \mathrm{m}$
(Tm:YAG) versus $715 \pm 142 \mu \mathrm{m}$ (Ho:YAG) (Tables 3, 4). Thus the increase of laser power does not affect or increase the laser damage zone significantly in the ambient air (Fig. 3).

The incision depth in ambient air on the low power setting was $346 \pm 199 \mu \mathrm{m}$ (Tm:YAG) and $118 \pm 119 \mu \mathrm{m}$ (Ho:YAG). On the high power setting, the incision depth was $5083 \pm 144$ versus $1126 \pm 383 \mu \mathrm{m}$ (Fig. 4). Therefore, the Tm:YAG laser is up to 4 times more efficient for incisions under the above mentioned conditions.

\section{Experiments in aqueous saline solution}

In the saline solution experiments the laser damage zone on the low power setting amounts to $550 \pm 137 \mu \mathrm{m}$ for the Tm:YAG and $447 \pm 65 \mu \mathrm{m}$ for Ho:YAG (Tables 5 , 6). On the high power setting we detected a laser damage zone of $653 \pm 111 \mu \mathrm{m}$ (Tm:YAG) and $677 \pm 134 \mu \mathrm{m}$ (Ho:YAG) (Tables 7, 8).

Incision depth in saline solution on the low power setting amounts to Ho:YAG $1214 \pm 888 \mu \mathrm{m}$. The Tm:YAG laser does not cut tissue at $5 \mathrm{~W}$ in saline solution.

The incision depth on the high power setting was $4050 \pm 1058 \mu \mathrm{m}$ (Tm:YAG) and $4083 \pm 520 \mu \mathrm{m}$ (Ho:YAG) (Fig. 5). Both lasers offer a comparable incision depth at their respective maximum power settings.

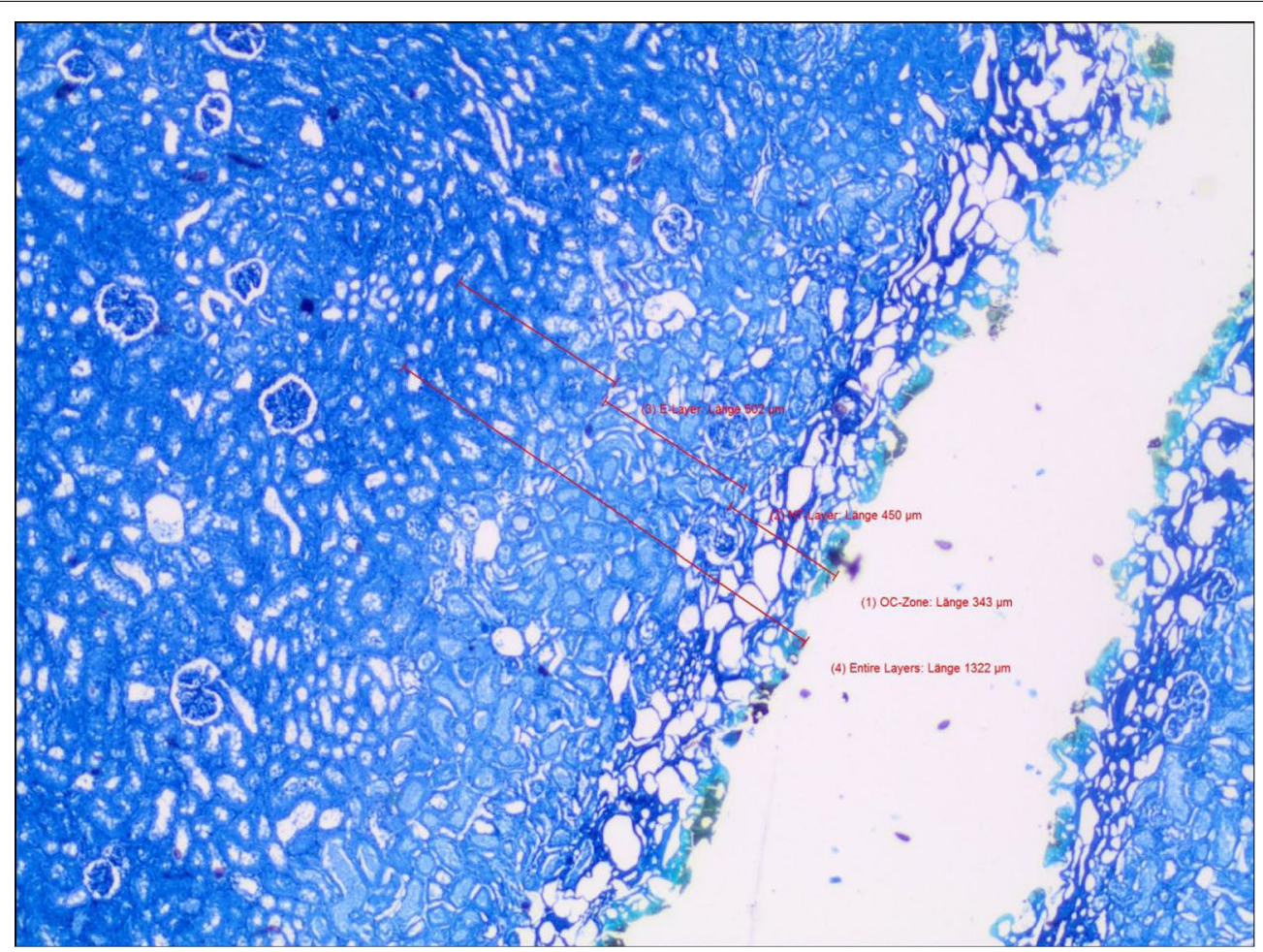

Fig. 1 Histologic specimen of a laser cut in porcine kidney by Tm:YAG at $120 \mathrm{~W}$ power in ambient air 


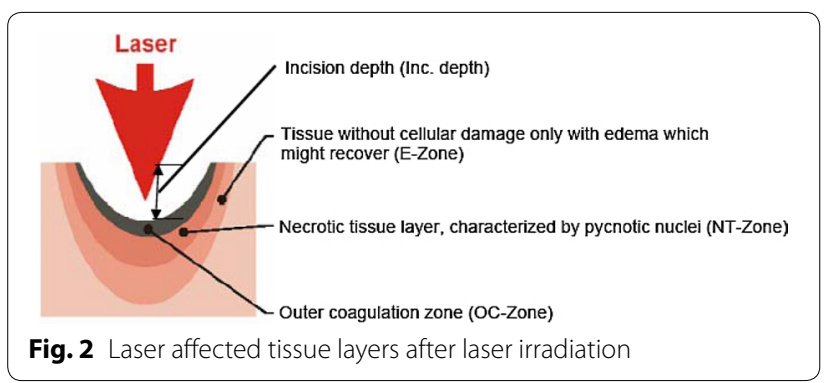

\section{Discussion}

Several lasers were introduced in urological surgery and stone treatment during the recent past. One of the most widely researched laser devices is the Ho:YAG laser. Holmium laser enucleation of prostate (HoLEP) has become a comparable treatment option to TUR in BPH therapy with advantages in the treatment of large prostatic adenomas (Herrmann et al. 2012; Gilling et al. 2000, 2012). In addition, the Tm:YAG laser was introduced and

Table 1 Laser damage zone of Tm:YAG at $5 \mathrm{~W}$ in ambient air

\begin{tabular}{lllllll}
\hline & OC-zone $(\boldsymbol{\mu m})$ & NT-zone $(\boldsymbol{\mu m})$ & E-zone $(\boldsymbol{\mu m})$ & Total $(\boldsymbol{\mu m})$ & OC + NT $(\boldsymbol{\mu m})$ & Inc. depth $(\boldsymbol{\mu m})$ \\
\hline A/K/R120/5W-1 & 382 & 348 & 298 & 1028 & 730 & 116 \\
A/K/R120/5W-2 & 294 & 425 & 292 & 1011 & 719 & 465 \\
A/K/R120/5W-4 & 440 & 346 & 257 & 1043 & 786 & 456 \\
Average & 372 & 373 & 282 & 1027 & 745 & 346 \\
SD & 74 & 45 & 16 & $119^{\text {a }}$ & 199 \\
\hline
\end{tabular}

a The measurement error of OC $+\mathrm{NT}$ is the total of the standard deviations of the OC-zone plus NT-zone

Table 2 Laser damage zone of Ho:YAG at $0.5 \mathrm{~J}, 10 \mathrm{~Hz}, 5 \mathrm{~W}$ in ambient air

\begin{tabular}{llllllr}
\hline & OC-zone $(\boldsymbol{\mu m})$ & NT-zone $(\boldsymbol{\mu m})$ & E-zone $(\boldsymbol{\mu m})$ & Total $(\boldsymbol{\mu m})$ & OC + NT $(\boldsymbol{\mu m})$ & Inc. depth $(\boldsymbol{\mu m})$ \\
\hline A/KNPS/0.5,10-1 & 328 & 408 & 284 & 1020 & 736 & 0 \\
A/KNPS/0.5,10-3 & 308 & 400 & 450 & 1158 & 708 & 116 \\
A/KNPS/0.5,10-5 & 177 & 222 & 501 & 900 & 399 & 237 \\
Average & 271 & 343 & 112 & 1026 & 614 & 118 \\
SD & 82 & 105 & 113 & 129 & $189^{\text {a }}$ & 119 \\
\hline
\end{tabular}

a The measurement error of OC + NT is the total of the standard deviations of the OC-zone plus NT-zone

Table 3 Laser damage zone of Tm:YAG at $120 \mathrm{~W}$ in ambient air

\begin{tabular}{|c|c|c|c|c|c|c|}
\hline & OC-zone $(\mu \mathrm{m})$ & NT-zone ( $\mu \mathrm{m})$ & E-zone $(\mu \mathrm{m})$ & Total $(\mu \mathrm{m})$ & $\mathrm{OC}+\mathrm{NT}(\mu \mathrm{m})$ & Inc. depth $(\mu \mathrm{m})$ \\
\hline A/K/R120/120W-2 & 343 & 450 & 302 & 1095 & 793 & 5250 \\
\hline A/K/R120/120W-3 & 373 & 329 & 472 & 1174 & 702 & 5000 \\
\hline A/K/R120/120W-4 & 251 & 535 & 633 & 1419 & 786 & 5000 \\
\hline Average & 322 & 438 & 469 & 1229 & 760 & 5083 \\
\hline SD & 64 & 104 & 166 & 169 & $167^{\mathrm{a}}$ & 144 \\
\hline
\end{tabular}

a The measurement error of OC + NT is the total of the standard deviations of the OC-zone plus NT-zone

Table 4 Laser damage zone of Ho:YAG at $2 \mathrm{~J}, 40 \mathrm{~Hz}, 80 \mathrm{~W}$ in ambient air

\begin{tabular}{|c|c|c|c|c|c|c|}
\hline & OC-zone $(\mu \mathrm{m})$ & NT-zone $(\mu \mathrm{m})$ & E-zone $(\mu \mathrm{m})$ & Total $(\mu \mathrm{m})$ & $\mathrm{OC}+\mathrm{NT}(\mu \mathrm{m})$ & Inc. depth $(\mu \mathrm{m})$ \\
\hline $\mathrm{A} / \mathrm{KA} / \mathrm{PS} / 2,40-2$ & 215 & 434 & 434 & 1083 & 649 & 1432 \\
\hline A/KNPS/2,40-3 & 247 & 378 & 654 & 1279 & 625 & 697 \\
\hline A/KA/PS/2,40-6 & 327 & 544 & 325 & 1196 & 871 & 1250 \\
\hline Average & 263 & 452 & 471 & 1186 & 715 & 1126 \\
\hline SD & 58 & 84 & 168 & 98 & $142^{a}$ & 383 \\
\hline
\end{tabular}

${ }^{a}$ The measurement error of OC + NT is the total of the standard deviations of the OC-zone plus NT-zone 

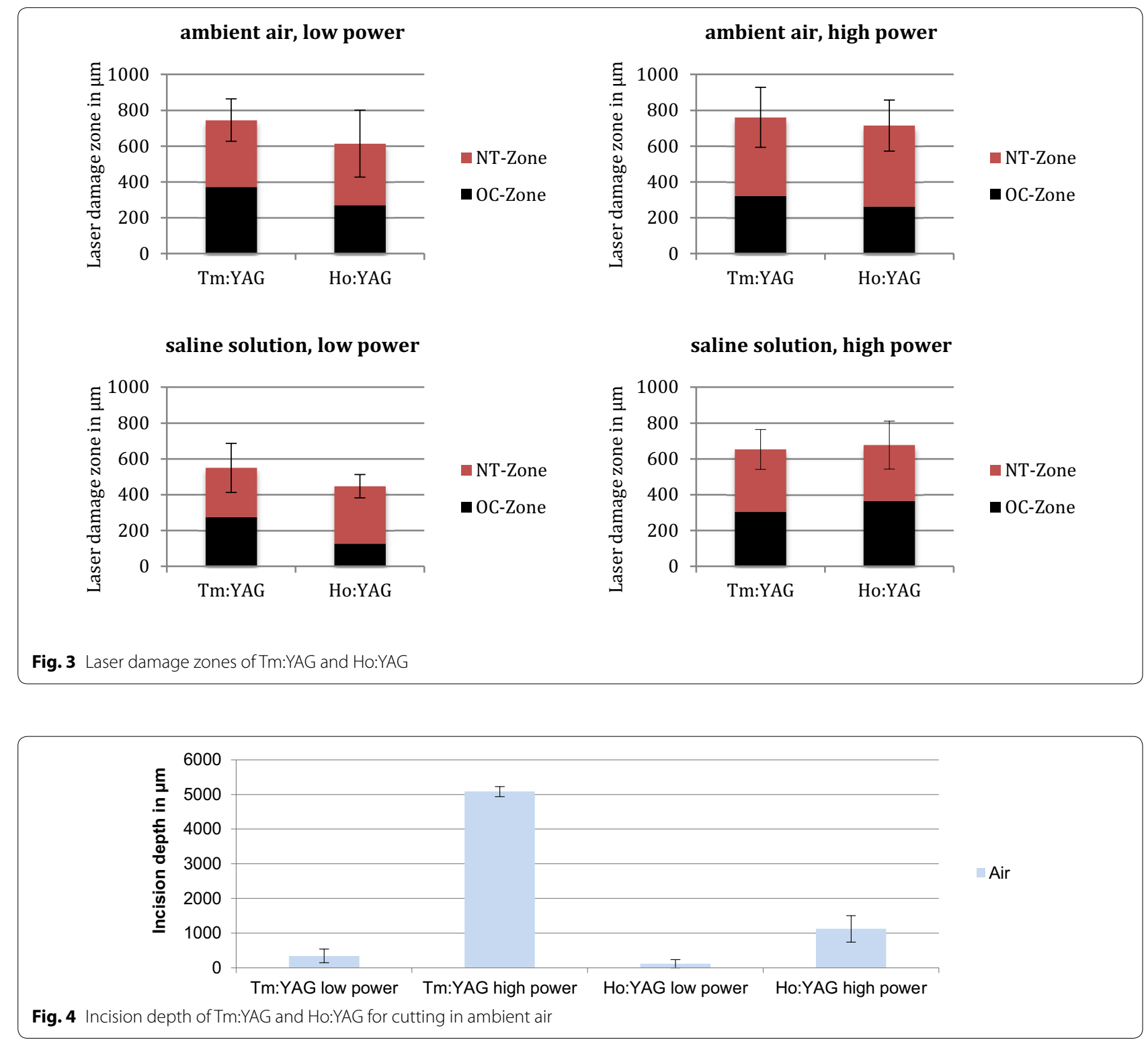

showed convincing results for treatment of $\mathrm{BPH}$ in several studies (Bach et al. 2010; Netsch et al. 2012). Based on the different physical properties of each laser system, additional ex vivo experiments are necessary to understand the effect on tissue and to assess the complications and the clinical outcome after surgery.

The laser damage zone is defined by irreversible tissue damage due to laser irradiation (Bach et al. 2010). This damage zone is related but not identical to the absorption length at the laser wavelength in water. At the Tm:YAG laser wavelength of $2013 \mathrm{~nm}$, the absorption length in water is $165 \mu \mathrm{m}$ and approximately $426 \mu \mathrm{m}$ at the Ho:YAG wavelength of $2123 \mathrm{~nm}$ (Irvine and Pollack 1968). Due to heat diffusion, the laser damage zone extends deeper into the irradiated tissue than the absorption length (Herrmann et al. 2012). The experiments described above reveal a laser damage zone into porcine kidney by the Tm:YAG laser of $550-760 \mu \mathrm{m}-$ depending on the ambient medium (aqueous saline solution or ambient air). The laser power delivered to tissue has less influence on the extent of the laser damage zone than the ambient medium (aqueous saline solution or ambient air). The laser damage zone by the Ho:YAG laser $(450-714 \mu \mathrm{m})$ compares favorably to the Tm:YAG laser. The present data is akin to the recently published examinations for porcine kidney (Bach et al. 2010; Kang et al. 2010).

The emission of the Ho:YAG laser is pulsed. Pulses of up to $6 \mathrm{~kW}$ peak power and approximately $250 \mu \mathrm{s}$ 
Table 5 Laser damage zone of Tm:YAG at $\mathbf{5} \mathbf{W}$ in aqueous saline solution

\begin{tabular}{lllllll}
\hline & OC-zone $(\boldsymbol{\mu m})$ & NT-zone $(\boldsymbol{\mu m})$ & E-zone $(\boldsymbol{\mu m})$ & Total $(\boldsymbol{\mu m})$ & OC + NT $(\boldsymbol{\mu m})$ & Inc. depth $(\boldsymbol{\mu m})$ \\
\hline Aq/K/R120/5W-3 & 255 & 221 & 344 & 820 & 476 & 0 \\
Aq/K/R120/5W-5 & 355 & 260 & 343 & 958 & 615 & 0 \\
Aq/K/R120/5W-6 & 212 & 346 & 309 & 867 & 558 & 0 \\
Average & 274 & 276 & 332 & 882 & 550 & 0 \\
SD & 73 & 64 & 20 & 70 & $137^{\text {a }}$ & 0 \\
\hline
\end{tabular}

${ }^{a}$ The measurement error of $\mathrm{OC}+\mathrm{NT}$ is the total of the standard deviations of the OC-zone plus NT-zone

Table 6 Laser damage zone of Ho:YAG at $0.5 \mathrm{~J}, 10 \mathrm{~Hz}, 5 \mathrm{~W}$ in aqueous saline solution

\begin{tabular}{llllllr}
\hline & OC-zone $(\boldsymbol{\mu m})$ & NT-zone $(\boldsymbol{\mu m})$ & E-zone $(\boldsymbol{\mu m})$ & Total $(\boldsymbol{\mu m})$ & OC + NT $(\boldsymbol{\mu m})$ & Inc. depth $(\boldsymbol{\mu m})$ \\
\hline Aq/KNPS/0.5.10-2 & 130 & 323 & 373 & 826 & 453 & 819 \\
Aq/KNPS/0.5,10-4 & 131 & 378 & 396 & 905 & 509 & 2231 \\
Aq/KNPS/0.5,10-6 & 116 & 264 & 420 & 800 & 380 & 593 \\
Average & 126 & 322 & 24 & 844 & 447 & 1214 \\
SD & 8 & 57 & 55 & $65^{\text {a }}$ & 888 \\
\hline
\end{tabular}

a The measurement error of OC $+\mathrm{NT}$ is the total of the standard deviations of the OC-zone plus NT-zone

Table 7 Laser damage zone of Tm:YAG at $120 \mathrm{~W}$ in aqueous saline solution

\begin{tabular}{|c|c|c|c|c|c|c|}
\hline & OC-zone $(\mu \mathrm{m})$ & NT-zone $(\mu \mathrm{m})$ & E-zone $(\mu \mathrm{m})$ & Total $(\mu \mathrm{m})$ & $\mathrm{OC}+\mathrm{NT}(\mu \mathrm{m})$ & Inc. depth $(\mu \mathrm{m})$ \\
\hline $\mathrm{Aq} / \mathrm{K} / \mathrm{R} 120 / 120 \mathrm{~W}-1$ & 318 & 330 & 350 & 998 & 648 & 5250 \\
\hline Aq/K/R12CV120W-5 & 274 & 275 & 393 & 942 & 549 & 3650 \\
\hline Aq/K/R12CV120W-6 & 320 & 442 & 373 & 1135 & 762 & 3250 \\
\hline Average & 304 & 349 & 372 & 1025 & 653 & 4050 \\
\hline SD & 26 & 85 & 22 & 99 & $111^{\mathrm{a}}$ & 1058 \\
\hline
\end{tabular}

a The measurement error of $\mathrm{OC}+\mathrm{NT}$ is the total of the standard deviations of the OC-zone plus NT-zone

Table 8 Laser damage zone of Ho:YAG at $2 \mathrm{~J}, 40 \mathrm{~Hz}, 80 \mathrm{~W}$ in aqueous saline solution

\begin{tabular}{|c|c|c|c|c|c|c|}
\hline & OC-zone $(\mu \mathrm{m})$ & NT-zone $(\mu \mathrm{m})$ & E-zone $(\mu \mathrm{m})$ & Total $(\mu \mathrm{m})$ & $\mathrm{OC}+\mathrm{NT}(\mu \mathrm{m})$ & Inc. depth $(\mu \mathrm{m})$ \\
\hline $\mathrm{Aq} / \mathrm{KNPS} / 2,40-1$ & 278 & 292 & 432 & 1002 & 570 & 3500 \\
\hline $\mathrm{Aq} / \mathrm{KNPS} / 2,40-4$ & 321 & 318 & 600 & 1239 & 639 & 4500 \\
\hline $\mathrm{Aq} / \mathrm{KNPS} / 2,40-5$ & 497 & 326 & 719 & 1542 & 823 & 4250 \\
\hline Average & 365 & 312 & 584 & 1261 & 677 & 4083 \\
\hline SD & 116 & 18 & 144 & 271 & $134^{\mathrm{a}}$ & 520 \\
\hline
\end{tabular}

${ }^{a}$ The measurement error of $\mathrm{OC}+\mathrm{NT}$ is the total of the standard deviations of the OC-zone plus NT-zone

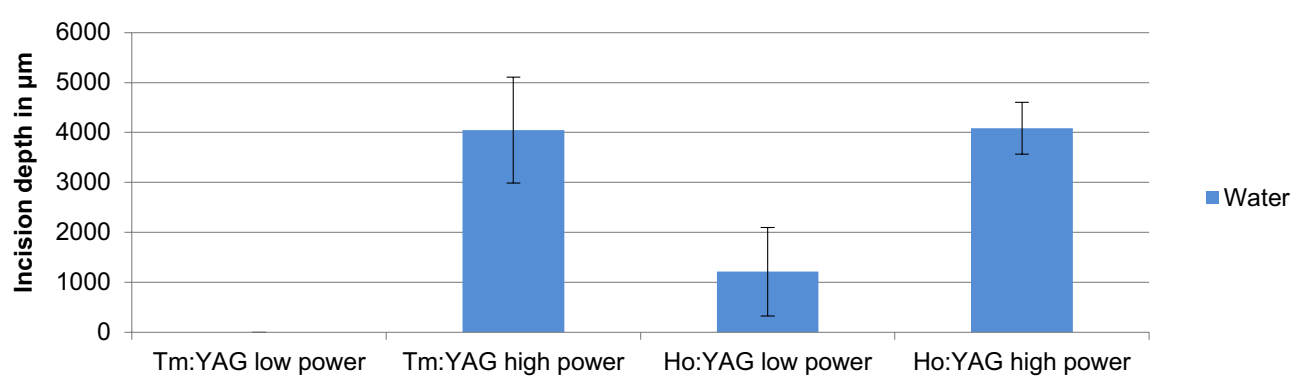

Fig. 5 Incision depth of Tm:YAG and Ho:YAG for cutting in aqueous saline solution 
duration are separated by more than $20-100$ ms depending on the selected laser pulse repetition rate. The high laser pulse peak power of several kilowatts $(\mathrm{kW})$ leads to explosive vaporization of tissue. Between laser pulses the generated heat dissipates into the surrounding tissue. The laser damage zone by the Ho:YAG laser in ambient air is slightly less than the laser damage zone by the continuously emitting Tm:YAG laser. The laser damage zone does not vary with the laser power, rather it relies on methodical variations such as translation speed or angulation of the laser fiber with respect to the tissue. The incision created by the Tm:YAG is smoother and deeper when compared to the Ho:YAG laser (Teichmann et al. 2007). The smoother Tm:YAG incision allows for simplified identification of anatomic landmarks than with incisions by the Ho:YAG laser. The smoother incisions by the Tm:YAG laser possibly translates into an easier learning curve for incising and resecting laser based techniques. This correlates with the rising interest in Tm:YAG based techniques for the treatment of the bladder outlet obstruction (BOO) due to benign prostatic enlargement (BPE) (Herrmann et al. 2010, 2012; Cui et al. 2014; Netsch et al. 2013; Wei et al. 2013).

A limitation of the study may be that experiments were not carried out in a perfused kidney model as in some other studies. The present experiments were performed on ex vivo porcine kidneys as a model for prostate surgery. Recent studies confirmed that a perfused ex vivo kidney model is a consistent model for prostate surgery (Michel et al. 1996). Studies comparing different therapy modalities such as bipolar electro cautery, diode-, KTP- and thuliumlasers to evaluate the laser damage zones and hemostatic effects of these surgery devices were performed (Heinrich et al. 2010; Wendt-Nordahl et al. 2008; Michel et al. 1996; Wendt-Nordahl et al. 2007). In the present experiments we used a non-perfused kidney model as a model for prostate surgery. It was shown that none-perfused kidneys are sufficient for the examination of laser damage zones as safety criteria for laser surgery because the laser damage zones in perfused and none perfused porcine kidneys are similar (Khoder et al. 2012). The in vivo effects may be different, especially for laser use on prostate tissue.

Another limitation of the present study is that any comparison of a pulsed laser with a continuous wave laser is very difficult due to fundamental differences in laser beam tissue interaction by the properties of heat conduction and heat excess-thermal relaxation time.

A further limitation of the study is that all variances in tissue composition with regard to waterlevel can alter the immediate tissue effect and lead to different results for laser effect. We tried to consider this fact by comparing the arithmetic mean of three equal experiments for each setting.

\section{Conclusion}

Our study demonstrates that Tm:YAG lasers and Ho:YAG lasers emitting laser radiation at approximately $2 \mu \mathrm{m}$ share similar properties with regard to tissue interaction, whereas Tm:YAG being a continuous wave laser could demonstrate higher capacity for vaporization when compared to Ho:YAG. This translates into better performance in resecting and vaporizing approaches for soft tissue surgery. Both create similar necrotic and outer coagulation zones. The laser damage zone is about $1 \mathrm{~mm}$ and similar for both laser generators. These in vitro studies correspond well with histologic measurements for in vivo measurements in prostate and kidney.

The Ho:YAG has proved to be a versatile laser in urology. The Tm:YAG laser offers equivalent tissue cutting performance, hemostasis, and safety for soft tissue applications while also providing higher vaporization capacities. The Tm:YAG is a safe, effective and reliable surgical device for many applications in urology and other surgical disciplines.

\section{Abbreviations \\ Tm:YAG: thulium yttrium aluminium garnet; Ho:YAG: holmium yttrium aluminium garnet; W: watt; kW: kilowatt; J: joule; Hz: hertz; mm: millimeter; cm: centimeter; $\mu \mathrm{m}$ : micrometer; $\mathrm{nm}$ : nanometer; KTP: potassium-titanyl- phosphate-laser; LBO: lithium-borate-laser; ${ }^{\circ} \mathrm{C}$ : degree celsius; s: second; ms: millisecond; $\mu \mathrm{s}$ : microsecond; $\mathrm{h}$ : hour; $\mathrm{NaCl}$ : sodium chloride; E-zone: edema zone; OC-zone: outer coagulation zone; NT-zone: necrotic tissue zone; HoLEP: holmium laser enucleation of the prostate; TUR: trans-urethral resection; $\mathrm{BPH}$ benign prostatic hyperplasia; BOO: bladder outlet obstruction; BPE: benign prostate enlargement.}

\section{Authors' contributions}

SJ participated in the design of the study and performed data analyses and interpretation. SJ mainly drafted the manuscript. MW has been involved in drafting the manuscript and revised it critically. MK has been involved in drafting the manuscript and revised it critically. TB was involved in data analysis and revised the manuscript critically. HOT has made substantial contributions to conception and design of the study and to interpretation of data. AE was involved in conception of the study, acquisition, analysis and interpretation of data. He also critically revised the manuscript. SB was involved in conception and data acquisition, especially for the histopathological part of the study. TRWH was has made contributions to the conception and design and made substantial contributions in data interpretation. He was also involved in the draft and finalization of the manuscript. All authors read and approved the final manuscript

\section{Author details}

${ }^{1}$ Department of Urology and Urological Oncology, Hannover Medical School (MHH), Carl Neuberg Str. 1, 30625 Hannover, Germany. ${ }^{2}$ Department of Urology, Asklepios Hospital Harburg, Eissendorfer Pferdeweg 52, 21075 Hamburg, Germany. ${ }^{3}$ LISA Laser Products OHG, Max-Planck-Strasse 1, 37191 Katlenburg-Lindau, Germany. ${ }^{4}$ MVZ wagnerstibbe Pathologie, Neuropathologie und Laboratoriumsmedizin, An der Lutter 24, 37075 Göttingen, Germany. ${ }^{5}$ Department of Urology, Clinic of the University of Schleswig Holstein / Campus Luebeck, Ratzeburger Allee 160, 23538 Lübeck, Germany.

\section{Competing interests}

HOT is the director of LISA Laser Products OHG, one of the manufacturer of the utilized laser devices. The Revolix laser was provided free of charge for the study. AE is employer of LISA Laser Products OHG, one of the manufacturer of the utilized laser devices. All other authors declare that they have no competing interests. 
Received: 20 July 2015 Accepted: 12 February 2016

Published online: 03 March 2016

\section{References}

Bach T, Herrmann TR, Ganzer R, Burchardt M, Gross AJ (2007) RevoLix vaporesection of the prostate: initial results of 54 patients with a 1-year followup. World J Urol 25:257-262

Bach T et al (2010) 70 versus 120 W thulium:yttrium-aluminium-garnet 2 micron continuous-wave laser for the treatment of benign prostatic hyperplasia: a systematic ex vivo evaluation. BJU Int 106:368-372

Cui D et al (2014) A randomized trial comparing thulium laser resection to standard transurethral resection of the prostate for symptomatic benign prostatic hyperplasia: four-year follow-up results. World J Urol 32:683-689

Fried NM, Murray KE (2005) High-power thulium fiber laser ablation of urinary tissues at 1.94 microm. J Endourol 19:25-31

Gilling PJ, Kennett KM, Fraundorfer MR (2000) Holmium laser enucleation of the prostate for glands larger than $100 \mathrm{~g}$ : an endourologic alternative to open prostatectomy. J Endourol 14:529-531

Gilling PJ et al (2012) Long-term results of a randomized trial comparing holmium laser enucleation of the prostate and transurethral resection of the prostate: results at 7 years. BJU Int 109:408-411

Gupta PK (2007) Is the holmium:YAG laser the best intracorporeal lithotripter for the ureter? A 3-year retrospective study. J Endourol 21:305-309

Heinrich E et al (2010) $120 \mathrm{~W}$ lithium triborate laser for photoselective vaporization of the prostate: comparison with $80 \mathrm{~W}$ potassium-titanylphosphate laser in an ex vivo model. J Endourol 24:75-79

Herrmann TR et al (2010) Thulium laser enucleation of the prostate (ThuLEP): transurethral anatomical prostatectomy with laser support. Introduction of a novel technique for the treatment of benign prostatic obstruction. World J Urol 28:45-51
Herrmann TR, Liatsikos EN, Nagele U, Traxer O, Merseburger AS (2012) EAU guidelines on laser technologies. Eur Urol 61:783-795

Irvine WM, Pollack JB (1968) Infrared optical properties of water and ice spheres. Icarus 8(1-3):324-360

Kang HW, Kim J, Peng YS (2010) In vitro investigation of wavelength-dependent tissue ablation: laser prostatectomy between $532 \mathrm{~nm}$ and 2.01 micron. Lasers Surg Med 42:237-244

Khoder WY et al (2012) Ex vivo comparison of the tissue effects of six laser wavelengths for potential use in laser supported partial nephrectomy. J Biomed Opt 17:068005

Michel MS, Kohrmann KU, Weber A, Krautschick AW, Alken P (1996) Rotoresect: new technique for resection of the prostate: experimental phase. J Endourol 10:473-478

Netsch C, Bach T, Herrmann TR, Gross AJ (2012) Thulium:YAG VapoEnucleation of the prostate in large glands: a prospective comparison using 70- and 120-W 2-micron lasers. Asian J Androl 14:325-329

Netsch C, Bach T, Herrmann TR, Neubauer O, Gross AJ (2013) Evaluation of the learning curve for Thulium VapoEnucleation of the prostate (ThuVEP) using a mentor-based approach. World J Urol 31:1231-1238

Pierre S, Preminger GM (2007) Holmium laser for stone management. World J Urol 25:235-239

Teichmann HO, Herrmann TR, Bach T (2007) Technical aspects of lasers in urology. World J Urol 25:221-225

Wendt-Nordahl G et al (2007) 980-nm diode laser: a novel laser technology for vaporization of the prostate. Eur Urol 52:1723-1728

Wendt-Nordahl G et al (2008) Systematic evaluation of a recently introduced 2-micron continuous-wave thulium laser for vaporesection of the prostate. J Endourol 22:1041-1045

Wei H et al (2013) Thulium laser resection versus plasmakinetic resection of prostates larger than $80 \mathrm{ml}$. World J Urol 32(4):1077-1085. doi:10.1007/ s00345-013-1210-4

\section{Submit your manuscript to a SpringerOpen ${ }^{\circ}$ journal and benefit from:}

- Convenient online submission

- Rigorous peer review

- Immediate publication on acceptance

- Open access: articles freely available online

- High visibility within the field

- Retaining the copyright to your article

Submit your next manuscript at $>$ springeropen.com 